\title{
EFFECT OF PRE MENSTRUAL SYNDROME ON QUALITY OF LIFE DURING ADOLESCENCE PERIOD
}

\author{
${ }^{1}$ Heba AbdElrehem Mohamed Zedan, ${ }^{2}$ Dr.Hend AbdAllah El Sayed, \\ ${ }^{3}$ Assist.Prof.Soad AbdElsalam Ramadan ${ }^{4}$ Prof.Dr.Galal Ahmed Elkholy \\ 1Demonstrator of Maternity and Gynecology of Nursing ,Faculty of Nursing, Mansoura University, 2 Lecturer of \\ Obstetrics and Woman Health Nursing, Faculty of Nursing, Benha University 3 Assistant Professor of Obstetrics \\ and Woman Health Nursing Faculty of Nursing, Benha University 4Professor of Obstetrics and Gynecology \\ Faculty of Medicine Benha University \\ Email: hebazedan85@gmail.com
}

\begin{abstract}
Background: Pre menstrual syndrome can affect adolescent girl health and have significant impact on adolescent girl's quality of life. Aim of the study was to assess the effect of pre menstrual syndrome on quality of life of adolescent girl. This aim was achieved through, assessing adolescent girl's health condition regarding pre menstrual symptoms and assessing the effect of pre menstrual syndrome on quality of life on adolescent girls. Descriptive design was used to achieve the aim of the study. Setting, the study was conducted at the secondary technical nursing school at Benha university hospital. Purposeful Sample included 200 nursing students, with pre menstrual syndrome, unmarried girl and free from any medical and obstetrics disorders that affect quality of life. Tools included structured interviewing questionnaire, pre menstrual self evaluation questionnaire, and the medical outcome study short form-36(SF-36) . Results:80\%aged more than 16 years with the mean age is $17.61 \pm 1.13,64 \%$ menstruated at $11-13$ years with the mean age is $13.32 \pm 1.22$, highly significant difference between the studied girls and pre menstrual syndrome physical and psychological symptoms $\mathrm{P}<0.001$, Quality of life score indicated that there were decline in all dimensions of life quality as degree of pre menstrual syndrome worsen among adolescent girls. Conclusion: pre menstrual syndrome during adolescence affect adolescent girl's quality of life and well-being. Recommendation: establish educational program for adolescent girl regarding managing pre menstrual syndrome
\end{abstract}

Key word: Adolescent girl, pre menstrual syndrome, quality of life.

\section{Introduction:}

Yesterday's girl, adolescent today's and tomorrow's mother. Approximately $9 \%$ of the world's population is in the age group of 10-19 years, as they are passing through transitional period, from childhood to adulthood, they are undergoing a lot of physical as well as psychological stress due to the changes taking place in the $\operatorname{body}^{(1)}$.

Menstruation is a landmark in every girl's life. It is a major physical even that transmits the female from girlhood to adulthood, menstrual cycles are not always regular or stable; they may be disturbed by many disorders which commonly occur at the extremes of reproductive age. The causes of menstrual disorders can be triggered by a number of different factors, such as hormone imbalances, genetic factors, and pelvic diseases. These disorders may be psychosomatic/physical including premenstrual syndrome (PMS) and dysmenorrhea ${ }^{(2)}$.

Adolescence as the age group of 10-19 years in girls. Adolescence is recognized as a turbulent period which signifies the transiton from girlhood to womanhood where the menstruation occur. The menstruation associated with many problems such as pre menstrual syndrome which have a great effect on girls life ${ }^{(3)}$. 
Pre menstrual syndrome defined as a group of menstrually related disorders is characterized by physical and psychological symptoms that vary with different phases of the menstrual cycle. These symptoms result in the deterioration of interpersonal relationship, personal health and function. The exact cause of pre menstrual syndrome is unknown but there is good relation between pre menstrual syndrome and ovulation. Symptoms occur 7-14 days before the onset of menstruation. After the onset of menstrual bleeding, the symptoms rapidly disappear and are usually gone within three to four days $^{(26)}$. Various biosocial and psychological causes have been proposed as the cause of the pre menstrual syndrome, including altered endorphin modulation of gonadotrophin secretion, abnormal serotonin function, presence of progesterone, smoking, eating a lot of salty foods which cause fluid retention, diet rich in beef or caffeine containing beverages, use of alcohol and low level of vitamins and minerals ${ }^{(4)}$.

The symptoms of pre menstrual syndrome include physical and psychological symptoms. The physical symptoms such as abdominal bloating, breast tenderness, back pain, pelvic pain, joint pain, headache muscle pain, insomnia, hypersomnia, increase/decrease appetite, swelling, heaviness, low energy, tired, weak and stay in bed. The psychological symptoms of pre menstrual syndrome is irritability, anxiety, depression, hostility, poor concentration, confusion, sad, mood swing, lonely, nervous, angry, social problem such as social withdrawal, impatient, feel out of control, cannot cope, less productive in school or home and interpersonal conflict these symptoms are very dangerous on girl health and life ${ }^{(5)}$.

Quality of life (QOL) is defined as an individual's perception of position in life in the context of the culture and value system in which individual live, and in relation to goals, expectations, standards and concerns. QOL is abroad-ranging concept affected in a complex way by the person's physical health, psychological state, level of independence, social relationship, and their relationship to salient feature so their environment ${ }^{(6)}$.

Quality of life is a concept that incorporates many aspects of an individual's experience, general well being and satisfaction, physical health, social relationship, and level of independence. Also quality of life is a subjective and multi-dimenations, it can be influenced by socioeconomic factors, age, gender, presence of disease and treatment ${ }^{(7)}$. Pre menstrual syndrome is known to have great impact on daily life activities and social functions of adolescent girls and might result in significantly decreased quality of life. Girls with pre menstrual syndrome had the worse quality of life score in all domains of quality of life such as physical function, psychological health, social function, pain, vitality, role limitation, health status, perception and health status change $\mathrm{e}^{(8)}$.

The medical treatment of pre menstrual syndrome include hormonal therapy and medication. The aim of hormonal therapy is to suppress ovulation and reduce the hormones of the pre menstrual phase. Medications are mood stabilizers and antidepressant can improve pre menstrual symptoms significantly. Anti-Prostaglandin and anti-inflammatory effective for breast pain and bloating. Non steroidal anti-inflammatory drugs help to reduce breast tenderness and pain. Vitamin B6 reduce irritability and bloating

.Calcium daily take prevent water retention, mood swing and cramps ${ }^{(9)}$.

The nursing intervention of pre menstrual syndrome include health education about diet, exercise, rest and sleep. Diet help in relieve physical and psychological symptoms of pre menstrual 


\begin{abstract}
syndrome. Diet must be rich in carbohydrates, green vegetables, salad, fruit, nuts, pasta, brown rice, dried beans, chicken and fish ${ }^{(10)}$.In addition, nursing intervention include psychological intervention to relieve pre menstrual syndrome such as relaxation therapy which include breathing exercise, meditation and yoga. Regular aerobic exercise also relieve pre menstrual syndrome. It may reduce fatigue, stress and depression. Aerobic exercise include brisk walking, running, cycling, and swimming. Exercise regularly at least 30 minutes of most days of the week. Exercise reduce physical and emotional stress. Exercise increase sense of well being, improve circulation. Adolescent girl must take adequate rest and sleep. Regular sleeping habit in which you wake up and go to sleep at the same times every day, including weekends may decrease moodiness and fatigue ${ }^{(11)}$
\end{abstract}

\section{Research questions}

Is there a relationship between pre menstrual syndrome and quality of life of adolescent girls?

To what extent pre menstrual syndrome affect the quality of life on adolescent girls?

\section{Subjects and Method \\ Study Design}

A descriptive design was used to achieve the aim of the study.

\section{Study Setting}

This study was conducted at the secondary technical nursing school at Benha University Hospital.

\section{Subjects:}

200 nursing students with pre menstrual syndrome were involved in the study sample during three months of data collection

\section{Tools:}

Three tools were used for collecting data I-Structured interviewing questionnaire:

This tool was developed by the researcher after review of current relevant of literature. It was designed in an Arabic language in the form of close and openended questions. It consisted of three parts (Appendix I).

Part(a) socio-demographic characteristics of the adolescent girls included age, class level, marital status, residence, mother's educational level, and mother's occupation. $\operatorname{Part}(\mathbf{b})$ menstrual history as age of menarche, duration, regularity and amount of blood.

Part(c) current complaints such abdominal bloating, breast tenderness, headache, back pain and pelvic pain.

II-Pre menstrual syndrome self evaluation questionnaire :

This tool was adopted from ${ }^{(27)}$. and was translated into Arabic language by the researcher. This scale was used to self evaluate whether the girl has pre menstrual syndrome or not, to determine the degree and the intensity of the pre menstrual symptoms. It was consisted of (18) items that describe both physical and psychological symptoms of pre menstrual syndrome. Physical symptoms(10) such as, weight gain, breast tenderness and headache. Psychological symptoms(8) such as nervous Tension, mood swings and irritability. (Appendix II)

\section{Scoring system:}

Each item was rated on a scale of 0 "no occurrence of a particular symptoms" to 4 "partially or completely disabled". The total score is dividing according to the following: 0 to 12 the girl do not have pre menstrual syndrome, 12 to 18 the girl have borderline to mild pre menstrual syndrome , 19 to 25 the girl have mild to moderate pre menstrual syndrome , 25 to 35 the girl have moderate to severe pre menstrual syndrome, 35 to 45 the girl have sever pre 
menstrual syndrome, score is 45 or greater the girl is disabling from pre menstrual syndrome.

\section{III- The medical outcome study short form-36(SF-36):}

This tool was adopted from ${ }^{(28)}$. and was translated into Arabic language to assess the effect of pre menstrual syndrome on quality of life of adolescent girls. The SF36 included both physical and mental concepts by 36 questions and each one has four-sub groups of the questions. For the physical component, the four sub groups are as follows: physical functioning, role limitation due to physical problems, bodily pain and general health perceptions. The four sub groups of the psychological component are: social function, general mental health, role limitation due to emotional problems and vitality (Appendix III).

\section{Ethical Considerations}

- Each girl was informed about the purpose and benefits of the study at the beginning of interview and time throughout the study.

- An oral consent was obtained from each girl before starting data collection.

- Confidentiality was ensured throughout the study process, where personal data were not disclosed, and the adolescent girls were assured that all data was used only for research purpose.

- Each girl was informed that, participation is voluntary and her withdrawal will not affect her care. .

\section{Pilot Study}

A pilot study was applied on $10 \%$ of total sample (20) adolescent girls with pre menstrual syndrome to assess the applicability and clarity of the tools. Necessary modifications were done based on the pilot study findings as some questions are omitted and others added as well as to estimate the time needed for each subject to fill in questions. The students in the pilot study were excluded from main study sample.

\section{Field work}

The field work of the current study was carried out from beginning of October 2014 to end of December 2014 covered three months. The study setting was visited three days/week (Saturday, Sunday and Monday) from 9Am to 12Pm. At the beginning of interview the researcher greeted the nursing student, introduced herself to each student included in the study, explained the purpose of the study, taken oral consent, assessed whether the student have pre menstrual syndrome or not, and assessed the degree and the intensity of the pre menstrual symptoms that took 10minutes. Then, filled an interviewing questionnaire sheet that took 10 minutes. Assessed the effect of pre menstrual syndrome on quality of life of adolescent girls through the medical outcome study short form-36(SF-36) which contains 36 questions that covers both physical and mental concepts that took 20 minutes. All question sheets take 40 minutes. The researcher collect data from 5:6 student every day.

Validity and reliability:

The tool was developed by the researcher after reviewing the relevant literature and tested for its content validity by a jury of 3 expertise in the obstetrics and woman health nursing field.

\section{Data analysis :}

Data analysis and presentation were represented as descriptive results in the form of frequency and percentage and mean and standard deviation

\section{Results}

Table 1:shows socio demographic characteristics of the studied subjects. It was clear that more than three quarters $80 \%$ have aged more than 16 years old with the mean age is $17.61 \pm 1.13$ years, more than half of the adolescent girls 59\% were in second years, more than half of them $53.5 \%$ were lived in rural 
EFFECT OF PRE MENSTRUAL SYNDROME ON QUALITY OF

area, more than two thirds of the adolescent girls $68 \%$ their mothers were secondary education and $83.5 \%$ of girl's mothers were housewives

Table 2: reveals that less than two thirds of the adolescent girls $64 \%$ menstruated at age 11-13 years old with the mean age is $13.32 \pm 1.22$ years old. Duration of menstruation of the studied adolescent girls was ranged from 4-8days, with the mean duration $4.99 \pm 1.34$ days, $66 \%$ have irregular cycle of menstruation. $41.5 \%$ have interval of menstrual cycle more than 28 day, with mean $26.98 \pm 3.61$ days and more than three quarters of them $85 \%$ have moderate amount of blood.

Table 3: reveals that there was a highly statistically significant difference between the studied adolescent girls regarding pre menstrual syndrome physical symptoms $(\mathrm{P}<0.001)$ week before menstruation, during menstruation and week after menstruation. Except craving for sweets.

Table 4: displays that there was a highly statistically significant difference $(\mathrm{P}<0.001)$ between the studied adolescent girls regarding pre menstrual syndrome psychological symptoms week before menstruation, during menstruation and week after menstruation.

Table(5): shows that the mean scores for general health, physical functioning, role limitation due to physical health, role limitation due to emotional problem, social function, pain, energy/fatigue and emotional wellbeing. With the mean of role limitation due to emotional problem was $79.0 \pm 26.24$, this is better quality of life. Meanwhile the mean of energy/fatigue was $33.0 \pm 18.53$, this is the worse quality of life.

Table (1): Distribution of the studied girl according to their socio demographic characteristics $(n=200)$

\begin{tabular}{|c|c|c|}
\hline \multirow{2}{*}{ Socio demographic data } & \multicolumn{2}{|c|}{ No $\mathbf{2 0 0}$} \\
\cline { 2 - 3 } & \multicolumn{2}{|c|}{} \\
\hline Age (years) & 40 & 20.0 \\
\hline$<16$ & 160 & 80.0 \\
\hline Mean \pm SD & \multicolumn{2}{|c|}{$17.61 \pm 1.13$} \\
\hline Class & 12 & 6.0 \\
\hline First & 118 & 59.0 \\
\hline Second & 70 & 35.0 \\
\hline Third & \multicolumn{2}{|c|}{} \\
\hline Residence & 107 & 53.5 \\
\hline Rural & 93 & 46.5 \\
\hline Urban & 9 & 4.5 \\
\hline Mother's education & 35 & 17.5 \\
\hline Illiterate & 136 & 68.0 \\
\hline Read and write & 20 & 10.0 \\
\hline High education & & 83.5 \\
\hline Mother's job & 167 & 16.5 \\
\hline Housewife & 33 & \\
\hline Working & & \\
\hline
\end{tabular}


Heba AbdElrehem Mohamed Zedan et. al.

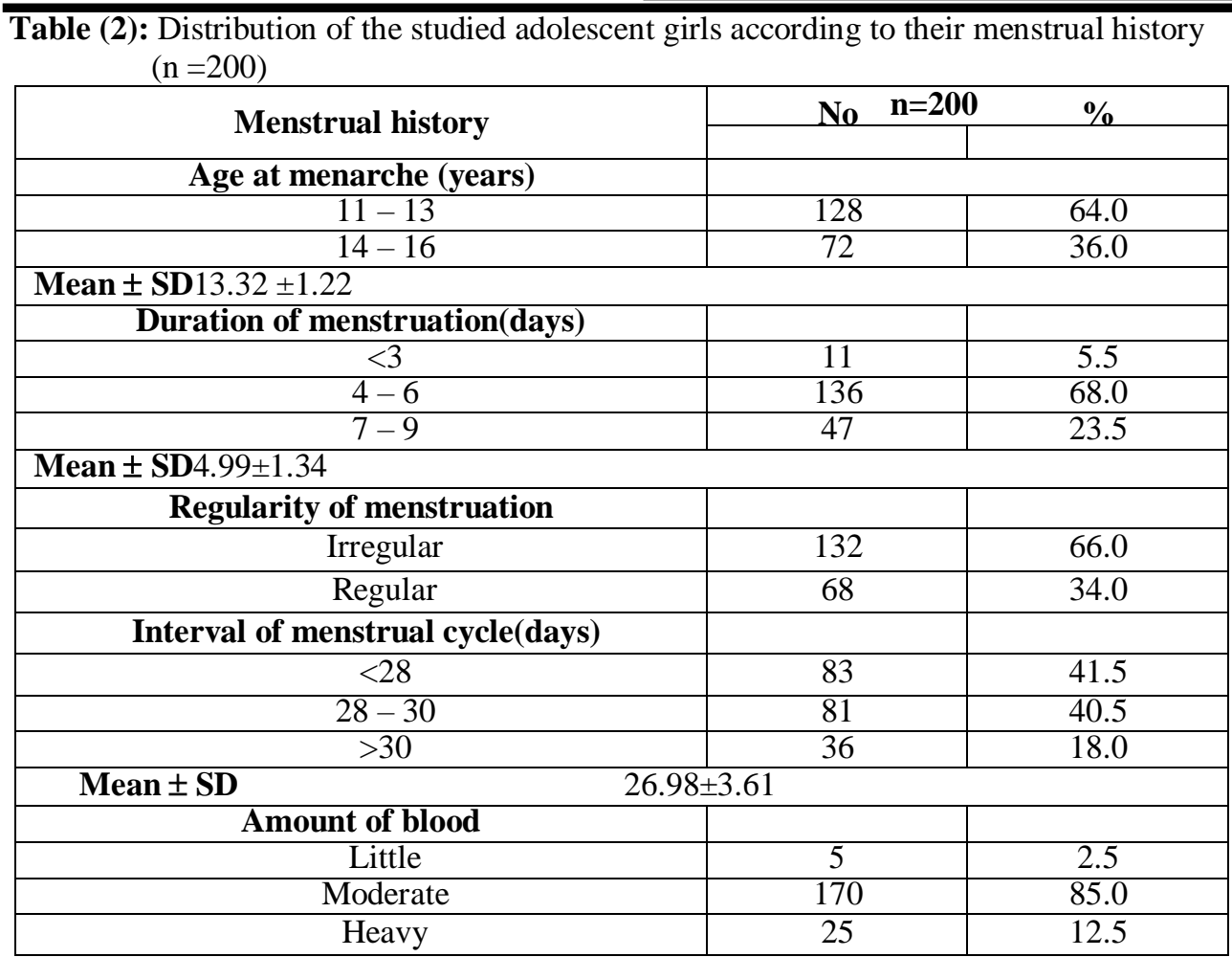

Table (3): Distribution of the studied adolescent girls according to Physical symptoms of premenstrual self-evaluation questionnaire) $n=200$ )

\begin{tabular}{|c|c|c|c|c|c|}
\hline $\begin{array}{c}\text { Physical } \\
\text { symptoms }\end{array}$ & $\begin{array}{c}\text { Week Before } \\
\text { menstruation }\end{array}$ & $\begin{array}{c}\text { During } \\
\text { menstruation }\end{array}$ & $\begin{array}{c}\text { Week After } \\
\text { menstruation }\end{array}$ & F & p \\
\hline $\begin{array}{c}\text { Swelling of } \\
\text { extremities }\end{array}$ & $1.08 \pm 0.27$ & $1.57 \pm 0.88$ & $1.08 \pm 0.26$ & 31.430 & $<0.001$ \\
\hline $\begin{array}{c}\text { Breast } \\
\text { tenderness }\end{array}$ & $1.42 \pm 0.76$ & $1.57 \pm 0.96$ & $1.09 \pm 0.29$ & 22.413 & $<0.001$ \\
\hline Headache & $2.08 \pm 0.94$ & $2.68 \pm 1.03$ & $1.34 \pm 0.67$ & 113.7 & $<0.001$ \\
\hline $\begin{array}{c}\text { Craving for } \\
\text { Sweets }\end{array}$ & $1.37 \pm 0.7$ & $1.54 \pm 0.94$ & $1.53 \pm 0.9$ & 2.353 & 0.096 \\
\hline $\begin{array}{c}\text { Increased } \\
\text { appetite }\end{array}$ & $1.27 \pm 0.61$ & $1.34 \pm 0.76$ & $1.56 \pm 0.85$ & 7.951 & $<0.001$ \\
\hline Heart Pounding & $1.82 \pm 0.85$ & $2.07 \pm 1.04$ & $1.46 \pm 0.76$ & 23.910 & $<0.001$ \\
\hline Fatigue & $2.36 \pm 1.06$ & $3.41 \pm 0.86$ & $1.59 \pm 0.72$ & 208.152 & $<0.001$ \\
\hline $\begin{array}{c}\text { Dizziness or } \\
\text { Fainting }\end{array}$ & $1.91 \pm 0.95$ & $2.64 \pm 1.22$ & $1.36 \pm 0.66$ & 87.077 & $<0.001$ \\
\hline Insomnia & $2.18 \pm 0.83$ & $3.38 \pm 0.9$ & $1.45 \pm 0.71$ & 282.675 & $<0.001$ \\
\hline Total score & $16.72 \pm 3.4$ & $21.36 \pm 4.09$ & $13.46 \pm 2.91$ & 257.28 & $<0.001$ \\
\hline
\end{tabular}

**A highly statistically significant difference $(\mathrm{P} \leq 0.001)$ 
EFFECT OF PRE MENSTRUAL SYNDROME ON QUALITY OF

\begin{tabular}{|c|c|c|c|c|c|}
\hline $\begin{array}{c}\text { Psychological } \\
\text { symptoms }\end{array}$ & $\begin{array}{l}\text { Week Before } \\
\text { menstruation }\end{array}$ & $\begin{array}{c}\text { During } \\
\text { menstruation }\end{array}$ & $\begin{array}{c}\text { Week After } \\
\text { menstruation }\end{array}$ & $\mathbf{F}$ & $\mathbf{p}$ \\
\hline & & $2.89 \pm 1.17$ & $1.21 \pm 0.58$ & 146.106 & $<0.001$ \\
\hline Mood Swings & $2.42 \pm 0.88$ & $3.24 \pm 1.02$ & $1.31 \pm 0.51$ & 271.890 & $<0.001$ \\
\hline Irritability & $1.63 \pm 0.86$ & $2.04 \pm 1.11$ & $1.25 \pm 0.72$ & 37.441 & $<0.001$ \\
\hline Anxiety & $2.12 \pm 0.89$ & $3.06 \pm 1.01$ & $1.35 \pm 0.68$ & 193.767 & $<0.001$ \\
\hline Depression & $1.55 \pm 0.91$ & $2.16 \pm 1.10$ & $1.27 \pm 0.66$ & 50.474 & $<0.001$ \\
\hline Forgetfulness & $1.27 \pm 0.62$ & $1.79 \pm 1.02$ & $1.25 \pm 0.67$ & 30.643 & $<0.001$ \\
\hline Crying & 1.570 .61 & $2.56 \pm 1.19$ & $1.17 \pm 0.48$ & 153.266 & $<0.001$ \\
\hline Confusion & $1.73 \pm 0.75$ & $2.63 \pm 1.25$ & $1.26 \pm 0.51$ & 121.433 & $<0.001$ \\
\hline Total score & $14.31 \pm 3.45$ & $20.35 \pm 5.12$ & $10.06 \pm 2.61$ & $\begin{array}{c}357.07 \\
0\end{array}$ & $<0.001$ \\
\hline
\end{tabular}

**A highly statistically significant difference $(\mathrm{P} \leq 0.001)$

Table (5): The short- From- 36 Health Survey domains mean and standard deviation $(n=200)$

\begin{tabular}{|c|c|c|}
\hline Domain & Range & Mean \pm SD \\
\hline General health & $8.3-79.2$ & $47.4 \pm 16.51$ \\
\hline Physical functioning & $15-95$ & $55.4 \pm 19.11$ \\
\hline Role limitation due to physical health & $25-100$ & $74.3 \pm 23.0$ \\
\hline Role limitation due to emotional problem & $33.3-100$ & $79.0 \pm 26.24$ \\
\hline Social function & $12.5-100$ & $58.9 \pm 22.15$ \\
\hline Pain & $12.5-90$ & $39.6 \pm 18.21$ \\
\hline Energy/fatigue & $0-75$ & $33.0 \pm 18.53$ \\
\hline Emotional wellbeing & $12-92$ & $48.1 \pm 16.13$ \\
\hline $\begin{array}{l}\text { Discussion } \\
\text { Premenstrual syndrome is a cyclic } \\
\text { recurrence of distressing somatic and } \\
\text { affective symptoms in the luteal phase of } \\
\text { menstrual cycle and in the few days (1- } \\
\text { 3days) of the next follicular phase, the } \\
\text { significant appearance of these symptoms } \\
\text { starts from the teen years and worsen } \\
\text { through the process of aging. It is notified } \\
\text { that } 80 \% \text { of the adolescent girls at the age } \\
\text { of reproduction have changes associated } \\
\text { with the premenstrual phase of the } \\
\text { menstrual cycle. Approximately, 20\% of } \\
\text { the adolescent girls stated that these } \\
\text { symptoms restrain them from daily } \\
\text { activities and } 10 \% \text { stated that the } \\
\text { symptoms are as heavy as to require } \\
\text { medical aid (12). }\end{array}$ & \multicolumn{2}{|c|}{$\begin{array}{l}\text { Regarding } \\
\text { characteristics of the studied adolescent } \\
\text { girls, the result of the present study found } \\
\text { that more than three quarters of them have } \\
\text { aged more than } 16 \text { years old with the mean } \\
\text { age was } 17.61 \pm 1.13 \text { years. more than half } \\
\text { of the adolescent girls were in second } \\
\text { years. Also more than half of them were } \\
\text { lived in rural area, more than two third of } \\
\text { the adolescent girls their mothers were } \\
\text { moderate education and more than three } \\
\text { quarters of them mothers were house wife. } \\
\text { This finding was agreed with (13) who } \\
\text { found in a cross-sectional survey of } 1,295 \\
\text { rural adolescent girls aged } 13 \text { to } 19 \text { years } \\
\text { with the mean age is } 17.3 \pm 1.1 \text { years in } \\
\text { Malaysia showed that most participants } \\
\text { identified themselves as having PMS. Also }\end{array}$} \\
\hline
\end{tabular}


this finding was agreed with (14) who found in study the mean age is17.5 \pm 1.3 years Also the present study results in the same line with ${ }^{(15)}$ who reported that mean age of study subjects were 17.6 years. This may be due to the subjects of the study included all adolescent nursing secondary school.

Regarding menstrual history, the finding of the current study reveals that less than two thirds of the adolescent girls menstruated at 11-13 years old with the mean age is $13.32 \pm 1.22$ years. This finding was supported by ${ }^{(16)}$ and found the mean age of menarche of his studied sample was $13.5 \pm 1.2$ years. Less than three quarters of them have menstrual duration 4-5 day, with the mean duration $4.99 \pm 1.34$ days. More than two third have length of menstrual cycle more than 28 day and more than three quarters of them have moderate amount of blood. This is agreed with the results of ${ }^{(17)}$ who found that all studied participants $100 \%$ was normal interval of menstruation. results were in agreement with ${ }^{(14)}$ who reported that majority of the students had menarche at age12, also the present study findings were similar to ${ }^{(18)}$ who reported that more than half of the students had menarche at age 13.Also, the finding of the present study showed that more than three quarters of the adolescent girls have back pain. This result is in accordance with the finding of (19) ${ }^{(20)}$ who mentioned that backache was the most reported complaint among the studied sample. Meanwhile ${ }^{(21)}$ reported that abdominal bloating was the most common complaint among the studied girl.

Regarding , physical symptoms of premenstrual syndrome the finding of the current study reveals that there was statistically highly significant relation between the studied adolescent girls and pre menstrual syndrome physical symptoms. This result is agreed with the results of ${ }^{(19)}$ who found that the most frequently physical symptoms reported by the studied students were: backache, fatigue, headache, bloating and breast tenderness. Also the result is agreed with the findings of ${ }^{(22)}$ who mentioned that backache, fatigue, bloating, breast tenderness and headache were the most common reported physical symptoms of PMS by the studied sample. Similar results were found by ${ }^{(23)}$ who reported that the most common somatic symptoms were backache, fatigue, headache, abdominal cramps and breast tenderness.

Regarding, psychological symptoms of premenstrual syndrome the finding of the current study reveals that there was statistically highly significant relation between the studied adolescent girls and pre menstrual syndrome psychological symptoms. The most common reported psychological symptoms were worry, nervous, mood swings, tension and depression. The current study findings were in agreement with ${ }^{(24)}$ who reported that more than half of students had PMS psychological signs and symptoms such as worry, nervous, mood swings, tension and depression. Also these findings were in the same line with ${ }^{(19)}$ who found that more than half of students had psychological signs and symptoms such as worry, nervous, mood swings, tension and depression.

Regarding, QOL domain the result of the current study indicated that there were decline in all dimensions of life quality as degree of PMS worsen among adolescent girls. This finding was in agreement with ${ }^{25}$ who found in their study that the life quality is significantly low in the adolescent girls who experience PMS complaints densely rather than the adolescent girls who experience slightly. Moreover, the result of the present study revealed that general health, bodly pain, energy and fatigue were represent the lowest score among other scales of QOL on the studied adolescent girls. This 
finding was in the same line with ${ }^{(24)}$ who found that the quality of life score in the mental and physical component in this sample was lower than the healthy population $(\mathrm{P}<0.001)$; where the most affected scales had the following order: role limitation due to emotional problems, role limitation due to physical problems, general health, vitality, social function, bodily pain, mental health and physical performance. Comparing the results of this study with our own, our study showed some similarities: role limitation due to emotional problems, role limitation to psychological aspects.

\section{Conclusion}

Pre menstrual syndrome is an intermittent problem that cannot be resolved until menopause. Also related to the research questions which stated that is there a relationship between pre menstrual syndrome and quality of life of adolescent girls? and to what extent pre menstrual syndrome affect the quality of life on adolescent girls? Pre menstrual syndrome have more effect on girl's quality of life. The findings from this study confirmed that adolescent girls with pre menstrual syndrome suffer from lower quality of life score in the mental and physical component. Therefore, the research questions were anserwered.

\section{Recommendation:}

Based on the findings of the present study, the following recommendations are suggested:

The findings suggest that health and educational authorities need to recognize the problem and provide appropriate, tangible and emotional support for adolescent girls with premenstrual syndrome at schools.

Pre menstrual syndrome adversely affects quality of life. It may be advantageous to refer adolescent girls with suspected PMS to advanced healthcare facilities for final diagnosis and treatment and to provide information on healthy diet.
Nurses have an important role in providing health education to adolescent girls about hygienic practices during menstruation and premenstrual syndrome through health classes, special programs and workshops concerning "counseling about premenstrual syndrome" to help adolescent girls understanding what her symptoms most likely represent, their causes, to enhance self- efficiency and self-management also the goals and components of treatment, recommendations for dietary modification and prescription of regular moderate aerobic exercise within the context for her life \& responsibilities.

Acknowledgments:

Words cannot adequately assure my deepest thanks and gratitude to Prof.Dr.Galal Ahmed Elkholy, Professor of Obstetrics and Gynecology Faculty of Medicine Benha University, for his unlimited help, constructive criticism, and continuous encouragement. It was by his continuous guidance that this work has come to light. I wish to express my deepest gratitude and sincere appreciation toward. Assist.Prof.Soad AbdElsalam Ramadan, Assistant Professor of Obstetrics and Woman Health Nursing, Faculty of Nursing, Benha University, who devoted much of her time, effort generous advice for the completion of this work. Words can never express my hearty thanks and indebtedness to her valuable advice experienced guidance and encouragement. I would like to express my deepest thanks and gratitude to Dr. Hend Abd El-Allah El-Sayed, Lecturer of Obstetrics and Woman Health Nursing, Faculty of Nursing, Benha University, for her valuable guidance and continuous encouragement, assistance and supervision throughout all phases of construction of the present work and forwarding her experience, to help me complete this work. 
Heba AbdElrehem Mohamed Zedan et. al.

References

1- Eswi., A et al. (2014) :Menstrual Attitude and Knowledge among Egyptian Female Adolescents. Journal of American Science. 2012;8(6):555565].(ISSN:1545-1003). http://www.americanscience. org.

2-Balamurugan, S., and Bendigeri, $\mathbf{N}$. ,(2015): Community-Based study of reproductive tract infections among women of the reproductive age group in the Urban Health Training Centre Area in Hubli, Karnataka, Indian $\mathbf{J}$ Community Med; 37(1): 34-38.

3-Kavitha, V., (2012): Reproductive Health and Hygiene among Adolescents, Language in India; 12(2) Available at www.languageinindia.com .Accessed September, 52012.

4- Bertone, J.,Hankinson, SE., and Bendich, A., (2014): Calcium and vitamin D intake and the risk of incident premenstrual syndrome. Arch Int Med, 165:1246.

5Lentz(2012):GM,LoboRA,GershensonD M,Katzvl,eds.comprehensive gynecology. ${ }^{\text {th }}$ ed.philadelphia,pa: MossbyElsevier;:chap.36.

6- Dontelle, R.J., (2012): Health the basic. $7^{\text {th }}$ ed Person Company. San Francisco, , Pp.13-29.

7- Woodill, A. Mendenhall, W.M. and Riggs, C.E. (2011):Treatment of head and neck burn. Burn: Principles and practice of skin disease,Philadelphia:Lippincott Williams ( $7^{\text {nd }}$ ed.), PP: 662- 732.

8-Rizk, D., Mosallam, M., Alyan, S., and Nagelkerke, N., (2012): Prevalence and impact of premenstrual syndrome in adolescent school girls in the United Arab Emirates. Acta Obstet Gynecol Scand.;85(5):589-98.

9- Jarvis, C.I., Lynch, A.M., and Morin, A.K., (2009): Management strategies for premenstrual

syndrome/premenstrual dysphoric disorder. Ann Pharmacotherapy; 42(7): 967-78.

10- Caan,S.B.,Walter,S.D.,Brazil.K., and Loeb,M.B.,(2009): Diet and sex hormones binding globulin Dysmeonrrhea, and pre menstrual symptoms., J.of obstet and Gynecol;95(2):395-8.

11- Byrne,A., and Byrne,D.G.,(2010): The effect of exercise on depression,anxiety and other mood states:areview.Jpsychosom res; 37:565-74.

12- Bertone, J.,Hankinson, SE., and Bendich, A., (2014): Calcium and vitamin $\mathrm{D}$ intake and the risk of incident premenstrual syndrome. Arch Int Med, 165:1246.

13- Wong, LP., (2012): Attitudes toward menstruation, menstrual-related symptoms, and premenstrual syndrome among adolescent girls: a rural school-based survey. Women Health, 51: 340-364.

14- Yassin, S.( 2012). Herbal remedy used by rural adolescent girls with menstrual disorders. Journal of American Science

15- Abu-Hashem, H., Amr, M., Allam,A.F.,and Yousef, H., (2010): Premenstrual syndrome in a sample of Egyptian adolescents. Egyptian Journal of Obstet and Gynecol.; 32:417-18.

16- Demir B, Algul LY, and Guven ES., (2012): Analysis of premenstrual syndrome incidence in medical staff and factors affecting premenstrual syndrome incidence. J Turkish Gynaecol Obstet Found, 3: 262-70.

17- Diaz, A.,Laufer, M.R., and Breech, L.L., (2009): Menstruation in girls and adolescents: using the menstrual cycle as a vital sign. Pediatrics; 118(5):2245-50. 
18- Carlson, B. M., (2014): Human Embryology and developmental biology $4^{\text {th }}$ Ed; 12: pp12-24.

19- Aly, S. A., (2010): Study of premenstrual syndrome among Assuit university students. pp: 63-64.

20- Backstrom T, Hammarback S., (2010): Premenstrual syndrome-psychiatric or gynaecological disorder? Annals of Medicine; 23(6):625-33.

21- Mekhail, N.R., (2014): The problem of premenstrual syndrome in general practice in EL-Salam district, Ismailia. Thesis MSC.,Suez canal university, faculty of Medicine.

22- Alvir, J.M., and Thys-Jacobs,S., (2012): premenstrualand menstrual symptoms cluster and response to calciumtreatment.

Psychopharmacology-Bull; 29(6), 145-148.

23- Ghonamy, G. E., (2013): The menstrual symptoms, self-care and attitude toward menstruation, among Cairo university students. Thesis MSC.,Cairo University, Faculty of Nursing. pp: 55-7.
24- Nisar, N., Zehra, N., Haider, G., Munir, A.A., and Sohoo, N. A., (2008): Frequency, intensity and impact of premenstrual syndrome in medical students. J Coll Physicians Surg Pak; 18(8) : 481-4.

25- Lustyk, M. K., Gerrish, W. G., Shaver, S., and Keys, S. L. (2009). Cognitive-behavioral therapy for premenstrual syndrome and premenstrual dysphoric disorder: a systematic review. [Review]. Arch Womens Ment Health, 12(2), 85-96. doi: 10.1007/s00737-009-0052-y.

26Brown,J.,O,Brien,P.M.,Marjoribank s,J.,andWyattk.,(2009):selective serotonin reuptake inhibitors for pre menstrualsyndrome.cochrane data base syst rev.15;(2):cd001396.

27-Allen,M.,D(2013) available at:http://preventivemedicinePS.com

28-

Ware,J.E.,\&Sherbourne,C.D.(1992). The mos 36-item short form health survey (SF-36).Medical 